\title{
Gonzalo Lamana, How "Indians" Think. Colonial Indigenous Intellectuals and the Question of Critical Race Theory, Tucson, The University of Arizona Press, 2019, 238 pp. ISBN 978-0-8165-3966-6
}

\section{Fernando Rodríguez Mansilla}

Hobart and William Smith Colleges

Geneva, New York

ESTADOS UNIDOS

Mansilla@hws.edu

[Hipogrifo, (issn: 2328-1308), 8.2, 2020, pp. 903-909]

Recibido: 01-06-2020 / Aceptado: 08-06-2020

DOI: http://dx.doi.org/10.13035/H.2020.08.02.58

El estudio How "Indians" Think encierra una propuesta, en principio, original: estudia las obras de Guaman Poma de Ayala y el Inca Garcilaso de la Vega como "intelectuales indígenas" y por ende voceros de una comunidad. Sus textos, en ese sentido, se enmarcarían dentro del activismo político. Para ello, Gonzalo Lamana emplea la denominada race theory, perspectiva crítica actual que explora los mecanismos de resistencia y supervivencia (survivance, en feliz matrimonio de ambos términos) de grupos raciales históricamente marginados, como los afrodescendientes y los nativos americanos. En su desarrollo de esta perspectiva, intelectuales afroamericanos (Frantz Fanon, James Baldwin) e indígenas norteamericanos (Gerald Vizenor, quien se identifica como tal) han propuesto y aplicado sus planteamientos a la producción cultural contemporánea con resultados convincentes. Ellos mismos han ejercido la escritura creativa, a la par de ensayos, para defender sus ideas a la vez que las plasman estéticamente. De igual forma, no cuesta encontrar, en la actualidad, ficciones y películas que se interpretan, con eficacia, desde la race theory. La pregunta metodológica que genera la propuesta de How "Indians" Think, entonces, sería: ¿cuán razonable o relevante dentro de la investigación dedicada a los siglos XVI y XVII resulta aplicar esta perspectiva crítica a las figuras y las obras de dos autores como Guaman Poma y el Inca Garcilaso? El autor no lo 
discute tan a fondo y lo establece como un axioma en la introducción del libro: «Their goal [de Guaman Poma y Garcilaso] was the same: to turn the readers themselves into instruments of change. In other words, they were Indians of a very special kind: activist intellectuals» (p. 11).

Tras lo señalado, la race theory, como otras perspectivas críticas recientes, asume algunos puntos de partida que, no obstante, cuesta encontrar en el periodo aquí estudiado. Me refiero en particular a la identidad y al cinismo obligatorio del lector, que son rasgos bastante extemporáneos para los siglos XVI y XVII. Son criterios válidos para evaluar textos actuales, pero, ¿cómo sostenerlos con textos cuyo marco de enunciación y horizonte de expectativas resultan tan distantes? De acuerdo con Lamana, el objetivo de las obras estudiadas (la Nueva Corónica y buen gobierno de Guaman Poma de Ayala y los Comentarios reales del Inca Garcilaso) no sería tanto criticar un orden de cosas (aspecto patente en ambos textos y que ya exploró largamente la crítica), sino cambiar la mentalidad de la gente o, mejor dicho, cambiar la percepción o la manera de ver a los indígenas que poseían los occidentales (identificados en su estudio como los "blancos" o los "españoles"). Lo cierto es que, en lo concerniente a la identidad indígena, las ideas en torno a esta categoría no eran tan uniformes o precisas en todos los textos, dado que se depende mucho de los contextos (historiografía, literatura, teología, etc.). El cinismo obligatorio es, por su parte, el criterio que permitiría encontrar ironía por doquier, como supuesto mecanismo de resistencia, pero tampoco se presenta todas las veces que se postula a lo largo del análisis. Resulta complicado aceptar, tal cual, la convicción del investigador en torno al fino uso de la ironía que permearía las obras de Guaman Poma y Garcilaso, dado que no se ofrece mayor documentación en torno a un lector de la época (español, indígena o mestizo) que hubiese captado ese doble sentido ni se refieren prácticas de lectura propias de la época afines a esta propuesta. De hecho, todo lo que sabemos de la recepción de la obra de Garcilaso en el siglo XVII es que la consume un público educado, conformado por otros intelectuales o bien funcionarios, españoles o identificables como tales, que sacó provecho de su lectura y lo erigió como autoridad historiográfica.

La primera parte del estudio se ocupa de las ideas de los españoles sobre los indígenas. La evidencia con la que se trabaja proviene, en general, de los manuales religiosos que exponen las aparentes limitaciones que presentaban los indígenas en el tiempo de la evangelización. Estos textos, evidentemente, tienden a infantilizar a los nativos y poco más se puede esperar de sus autores, para quienes la religión católica era un grado de civilización superior y no conocerla o ser renuente a ella indicaba, de antemano, un grado de inferioridad, así como la necesidad de redención, por lo que están impregnados de paternalismo. Estos prejuicios forman parte de la mentalidad de la época y, en aras de evitar maniqueísmos, tendrían que ser puestos en diálogo con otras tantas ideas encomiásticas sobre las culturas indígenas, que se filtraron a la literatura (especialmente el teatro) del Siglo Oro y que vuelven las "ideas españolas sobre los indígenas" un terreno un tanto más complejo. Los manuales religiosos apelan al retrato del indio con características de niño o tonto (al igual que en Garcilaso y en mucha de la producción textual de la época); en cambio, el "inca" es como el romano antiguo (con las limitaciones del gentil, pero con una 
serie de valores: inteligente, líder, valiente, etc.). Con todo, la categoría del "indio" como tonto o sujeto infantil es funcional en ciertos contextos (como el de los manuales religiosos abordados), pero no en todos. No funciona uniformemente, por ejemplo, con los indios guerreros que aparecen en la épica de La Araucana o con los indígenas nobles de una comedia como La aurora en Copacabana de Calderón de la Barca. Se requiere tener en cuenta la representación literaria de los indígenas en el Siglo de Oro para comprender que el "indio" recreado en los textos no es tanto una entidad orgánica (mucho menos una identidad política) como una "figura" o tipo social. El panorama se vuelve mucho más peliagudo cuando se considera los pocos lectores que tuvieron, relativamente, las crónicas de Indias, en comparación con la difusión masiva que tuvo el drama del Siglo de Oro: es más que seguro, por ende, que la imagen del indígena en la mentalidad peninsular bebiese de textos de Lope, Calderón y Tirso antes que de dos cronistas cuyo impacto entre la lectoría española es limitado y entre los indígenas todavía es ignorado, por falta de documentación.

Incluso con el anacronismo advertido (que uniformiza la categoría "indio" sin detenerse en sus matices), los planteamientos de la race theory tal vez se adaptan mejor a la figura y obra de Guaman Poma, partiendo del hecho de que este se identifica, indudablemente, como indio y hasta, dentro de la lógica de su discurso, cuestiona a los incas (que habrían perjudicado a los indios como colectivo), muestra elocuente de que se consideraban categorías diferentes. Es evidente que en la Nueva Corónica Guaman Poma propone una epistemología distinta, que incorpora elementos hispanos o europeos, pero subsumidos en una cosmovisión nativa novedosa. Trabajos clásicos como los de John Murra y Rolena Adorno han explorado esta notoria hibridez de la Nueva corónica. Como la bibliografía también lo ha establecido ya, la naturaleza del texto es la de una carta abierta dirigida a la máxima autoridad (el rey), con una serie de prácticas textuales adicionales, como el discurso del arbitrista (con propuestas de reforma) y el sermón.

En un texto así de complejo y lingüísticamente desafiante, las interpretaciones postmodernas de Lamana, a la caza de contradicciones o silenciamientos para detectar ironías y burlas a los que detentan la hegemonía (los españoles) pueden ser hasta cierto punto convincentes. Lo que el estudio no pondera con cautela es que muchos reclamos de Guaman Poma en torno a las injusticias eran tópicos y que el empleo de la hipérbole en torno a la pobreza y los abusos formaba parte de una larga tradición discursiva presente en textos escritos en español, tanto en la península como en América, con fines persuasivos y cuyo carácter retórico era socialmente aceptado. Sor Juana Inés de la Cruz también se quejaba de pobreza y se lamentaba de ser inculta, aunque su economía no era nada despreciable y su cultura estaba fuera de discusión'. Igualmente, un reformador como Cristóbal Pérez de Herrera cuenta anécdotas horripilantes sobre la mendicidad en las ciudades españolas de fines del XVI en su Amparo de pobres (1598) para agitar las mentes y dar paso a su propuesta de reforma social para remediar la crisis. En ese aspecto, la Nueva corónica no solo puede conectarse con esas prácticas textuales, sino que también

1. Ramírez Santacruz, Francisco, Sor Juana Inés de la Cruz. La resistencia del deseo, Madrid, Cátedra, 2019, p. 85. 
revela el afán de su autor de insertarse en ese circuito legal y cultural para que sus reclamos, legítimos, sean escuchados. Como resultado de la perspectiva teórica aplicada, la conclusión del análisis de la Nueva corónica no abandona la ponderación extemporánea de sus méritos, ya que, esencialmente, se propone validar la obra porque se ha proyectado al futuro. Así, se señala que Guaman Poma «anticipated later scholarly discoveries about the West» (p. 105), como la uniformización de los blancos al llegar al Nuevo Mundo o que en el espacio colonial se genera un estado de excepción (término de Giorgio Agamben) que, según acuñó Lamana en 2008, es permanente.

Algo parecido ocurre con el análisis dedicado al Inca Garcilaso, cuyos Comentarios reales serían «a text way ahead of its time. As a consequence, much of what I use to understand it comes not from sixteenth -or seventeenth- century tool kits (those of political theorists, philologists, theologians, or humanists) but from thinkers who would come centuries later; theories of race, thinkers of coloniality, experts in doubles meanings, and masters of writing and living under censorship» (p. 128). La consecuencia de este planteamiento es que, asumida la supuesta actualidad de la obra, el investigador no tiene ningún interés en comprender los desafíos del intelectual cuzqueño dentro de su tiempo, con sus alcances y sus límites. Al descartar, como Lamana mismo declara, una parcela de evidencia alrededor de los Comentarios reales, el análisis pierde rigor y se vuelve demasiado especulativo. Así, se menciona algunas veces, en lugares estratégicos del estudio (tanto para Garcilaso como para Guaman Poma, en verdad), el papel de la censura como argumento a favor de una escritura "entre líneas". Sin embargo, en ningún momento How "Indians" Think se preocupa en evaluar cómo operaba realmente la censura en torno a ciertos temas en la España del siglo XVII ni mucho menos la percepción que los intelectuales, de diversa laya, tenían en torno a ella. Contra el sentido común actual, estos la asumían como una circunstancia más de su escritura y hasta, en ocasiones, un mal necesario. El Inca Garcilaso era amigo de inquisidores, manejaba libros prohibidos y hasta consideraba que la censura de su traducción de los Diálogos de amor no era desatinada, dado que podía ser peligroso que una obra tan sofisticada cayese en manos del vulgo. En Quevedo y Cervantes se encuentran ideas similares. Considerando esto, pensar que Garcilaso no criticaría abiertamente la percepción de los españoles en torno a la infantilización de los indígenas por temor a una supuesta censura puede sonar creíble en la actualidad, pero no se presenta evidencia alguna de la validez de esa suposición a inicios del siglo XVII.

Similar anacronismo imaginativo guía otros aspectos del análisis de los Comentarios reales. De tal forma, asumiendo que Garcilaso era indio, o que se identificaba como tal, se supone que fingía un registro europeo y que se burlaba del público español culto al que se estaba dirigiendo. A la vez, el público nativo (aunque a nadie le consta esta experiencia de recepción) reconocería ese juego de ironías y por tanto Garcilaso le estaría dando estrategias para sobrevivir a la discriminación. Por eso, el texto satisfaría, por un lado, las exigencias de un modelo de escritura europeo; pero al mismo tiempo encerraría un ataque sutil, auténtica tomadura de pelo, al lector español, con pequeños textos (los "cuentecillos" áureos) protagonizados por indígenas, cuya carga subversiva se propone exponer Lamana. 
De nuevo, la hipótesis es sumamente atractiva, pero choca con una realidad histórica y cultural muy diferente alrededor del Inca Garcilaso. En primer lugar, la identidad indígena del historiador cuzqueño es susceptible de cuestionamiento. Él mismo, cuando debe identificarse dentro del panorama de castas surgido en el Perú, en el capítulo correspondiente a este tema dentro de los Comentarios reales (libro IX, cap. XXXI), se reconoce como mestizo. Sus usos del término "indio" para referirse a sí mismo obedecen a dos maniobras retóricas constantes en su texto: el recurso de autoridad de quien conoce el mundo recreado de primera mano (como cuando quiere sostener su conocimiento de la lengua o de la idiosincrasia de los nativos); y al mismo tiempo un mecanismo de falsa modestia (junto con proclamarse soldado, otro recurso frecuente) para ganar la simpatía de su lector y para que se le excusen posibles errores. Resulta dudoso, por ello, no solo considerar a Garcilaso un intelectual indígena, sino creer que él mismo se identificase como tal.

A esta observación debe sumarse otro hecho notorio: el análisis de la primera parte de los Comentarios reales (1609) es aislado y evita considerar el resto de la obra de Garcilaso, incluida la segunda parte de los Comentarios reales, que se publicó como Historia general del Perú (1617). Este último texto, junto a La Florida del Inca (1605), entraría ideológicamente en conflicto con muchas de las aseveraciones de Lamana en torno a las intenciones del cuzqueño. Tampoco conviene, a propósito, traer a cuento la biografía de Garcilaso, porque no encajaría en absoluto con ese perfil de activista proindígena que intenta diseñar este estudio; el Siglo de Oro no era, precisamente, un tiempo de intelectuales orgánicos. Cuesta, asimismo, creer en una sonrisa garcilasiana burlona o irónica frente a su público contemporáneo si se considera que la segunda parte de los Comentarios reales o Historia general del Perú se propone como una tragedia. Finalmente, al darle la espalda a muchos materiales del Siglo de Oro, el análisis incurre en algunas interpretaciones anacrónicas, ya no de índole teórica, sino producto de un desconocimiento de la lengua y la cultura de la época. Como resultado, se tergiversa el significado de algunos pasajes de los Comentarios reales, haciendo decir a su autor lo que nunca se propuso decir. Para ilustrarlo, solo abordaré dos de los cuentecillos analizados en How "Indians" Think, los cuales revelarían, según el investigador, sendas ironías que supondrían una burla al sujeto opresor (el español).

Para el cuento de los melones (pp. 167-172), hay que observar que el detalle que sostiene en buena parte la lectura subversiva que se hallaría en Garcilaso (que los indios no son castigados) también está presente en la versión de Francisco López de Gómara, aunque Lamana no parece recordarlo. Asimismo, da igual el orden de la presentación o que sean los mismos indígenas quienes cuentan al español lo ocurrido, ya que el narrador es omnisciente. Aunque ellos no lo hubiesen contado, el lector lo sabe, porque el narrador ya lo expuso. Ante la falta de evidencia textual, el investigador recrea un diálogo, totalmente inventado, que no se ciñe al cuentecillo, sino que imagina lo que los indios debieron pensar "realmente" al respecto, un elemento que el narrador no aborda ni mucho menos insinúa, porque no es relevante para la función eutrapélica del relato. En lugar de leer el cuentecillo reparando en las convenciones literarias de la época, es decir como un pasaje cómico con el sencillo 
objetivo de entretener, el análisis se esfuerza, sin mayor evidencia, en leerlo como un testimonio o documento de un supuesto malestar del propio Inca Garcilaso. En otras palabras: se lee en serio lo que solo tiene objetivo cómico.

El fenómeno contrario ocurre con el cuentecillo del rábano gigante (pp. 173-176): se toma a la ligera lo que es un asunto serio. Debe considerarse que la anécdota narrada entra en el mundo de las curiosidades y ese tipo de fenómenos se registraban con todos los legalismos posibles. Cuentecillos de ese estilo se encuentran en muchas recopilaciones y misceláneas de la época, en las cuales el autor (un intelectual o humanista) suele autorizar su testimonio a partir de un sujeto conocido, generalmente un noble o alguien acreditado de antemano por su virtud. El parlamento del caballero que pretende testimoniar la validez del tamaño del rábano puede tener, sin duda, su gracia y con ese fin lo reproduce Garcilaso: estas curiosidades tenían sus puntas de facecia o pasaje literario entretenido. No obstante, Lamana sostiene que lo ridículo de la situación se intensifica «in light of the Spanish idiomatic expression 'me importa un rábano'» (p. 174). El problema de este argumento es que entre los siglos XVI y XVII tal expresión no se empleaba, sino que su equivalente era «me importa un bledo» (incluida en el Diccionario de autoridades). La frase con el rábano es, en realidad, bastante moderna: solo se encuentra documentada a partir de 1886, en la pluma de Emilia Pardo Bazán². En el Siglo de Oro, la frase proverbial típica que se asocia con el rábano es «tomar el rábano por las hojas», sin valor cómico alguno, además de varias otras que son elogiosas: «Si quieres que te sepa bien la cena, ten rábanos y canela», «El rábano tierno de cualquier tamaño es bueno», «Como gavilán por rábanos», etc.; presentes todas estas en el Vocabulario de refranes de Gonzalo Correas.

De la mano con la impertinencia de la frase para considerar ridícula la situación del rábano, hay que añadir algo más: el que se requiera testigos para sostener la veracidad de un acontecimiento o que hasta se certifique con un funcionario asuntos extraordinarios no resultaba tan absurdo, como quiere Lamana, en la práctica historiográfica. Así procede Garcilaso en otros pasajes de los Comentarios reales, como cuando cuenta la manera en que una mona rompió los dientes a un tal Villacastín en Panamá, que avala con tres testimonios: el de la Historia general de las Indias de López de Gómara, la confirmación de un lector que hizo una nota al margen de su ejemplar de ese texto (presuntamente Gonzalo Silvestre), y su propio testimonio, pues dice haber conocido al soldado sin dientes en el Perú. Tras sumar los tres testimonios que certificarían el hecho, concluye: «Puse esto aquí con testigos, por ser cosa notable, y siempre que los hallare [testigos] holgaré presentarlos en casos tales [es decir 'notables']» (libro IX, cap. XXXVIII). Otro ejemplo de esta práctica: en la Historia general del Perú, de Cristóbal de Murúa, la aparición del hombre que volaba también se acredita como suceso notable con varios testigos y hasta

2. Navarro Carrascosa, Carles, «Me importa un bledo y expresiones similares: formación y evolución», Tendencias actuales en la investigación diacrónica de la lengua, Barcelona, Publicacions i Edicions de la Universitat de Barcelona, 2009, pp. 413-422. 
Ilega un comisario que los hace declarar bajo juramento (libro I, cap. LXXXVIII). Resulta difícil, por tanto, sostener que el cuentecillo del rábano tenga alguna carga cómica, entre líneas, que degradase al personaje del caballero hidalgo que quiere avalar lo que cuenta Garcilaso.

En conclusión, How "Indians" Think es un estudio innovador, muy oportuno para la agenda crítica actual (una aplicación original de la race theory), con resultados sugerentes en torno a la Nueva corónica (pese a su anacronismo), pero con dificultades de interpretación en torno a la obra y la figura del Inca Garcilaso de la Vega, debido a que soslaya aspectos lingüísticos, literarios y culturales que revelarían el sesgo de ciertos hallazgos. Sostener que Guaman Poma y el Inca Garcilaso eran «two native intellectuals [that] wanted to change the world» (p. 181) es muy bello y poderoso, pero a costa de esta proyección se lleva a cabo una lectura extemporánea de sus textos para atribuirles características que, ciñéndose a su sentido original, no poseen. 